\title{
Seletividade de Herbicidas Pós-Emergentes Aplicados na Soja Geneticamente ModificadA ${ }^{1}$
}

\author{
Selectivity of Post-Emergence Herbicides Applied on Genetically Modified Soybeans
}

\author{
NETO, M.E.F. ${ }^{2}$, PITELLI, R.A. ${ }^{3}$, BASILE E, A.G. ${ }^{4}$ e TIMOSSI, P.C. $^{5}$
}

\begin{abstract}
RESUMO - O experimento foi instalado em área de plantio comercial de soja Roundup Ready ${ }^{\circledR}$, na região do Pontal do Paranapanema, no municipio de Euclides da Cunha Paulista-SP, localizada a $20^{\circ} 43^{\prime} 11^{\prime \prime} \mathrm{S}$ e 50 $10^{\prime} 20^{\prime \prime} \mathrm{W}$, com uma altitude de $270 \mathrm{~m}$. A fase experimental foi conduzida de dezembro de 2006 a abril de 2007, sob sistema plantio direto, com uma temperatura média de $25^{\circ} \mathrm{C}$ e indice pluviométrico de $800 \mathrm{~mm}$. O solo da área experimental apresenta classe textural franco-argilo arenosa. Objetivou-se com este trabalho avaliar a eficácia e seletividade de glyphosate na formulação Roundup Transorb ${ }^{\circledR}$, associado aos herbicidas diclosulam, cloransulam-methyl, flumioxazina e S-metolachlor em duas modalidades de aplicação: única, com associação do glyphosate aos herbicidas; e uma sequencial apenas com glyphosate aos 15 DAA, no manejo das plantas daninhas trapoeraba (Commelina benghalensis) e corda-de-viola (Ipomoea triloba) durante o cultivo da soja. O experimento foi instalado no delineamento de blocos ao acaso, com 12 tratamentos e quatro repetições. Os tratamentos foram distribuídos em arranjo fatorial acrescido de duas testemunhas: sem capina manual e com capina manual. O arranjo fatorial 2 x 5 contemplou duas condições de aplicação dos herbicidas (única e sequencial) e cinco herbicidas (glyphosate, glyphosate + diclosulam, glyphosate + cloransulam-methyl, glyphosate + flumioxazin e glyphosate + S-metolachlor). Nas condições de produtos, épocas de aplicação e doses, os resultados mostraram que o herbicida glyphosate aplicado em dose única ou sequencial e suas combinações com diclosulam e cloransulam-methyl na primeira aplicação não promovem fitointoxicação nas plantas de soja. A combinação com flumioxazin e S-metolachlor promoveu atraso no crescimento das plantas e no fechamento da cultura, em razão do efeito na altura dos individuos e comprimento dos ramos. No tratamento com o S-metolachlor, isso pode ser explicado pelo fato de o herbicida ser registrado para controle em pré-emergência e ter sido aplicado em pós-emergência. Nenhum dos tratamentos influenciou significativamente a produção de grãos da cultura da soja. A aplicação única ou a complementação com aplicação sequencial de glyphosate promoveram excelente controle de Commelina benghalensis e Ipomoea triloba.
\end{abstract}

Palavras-chave: herbicidas, plantas daninhas, plantio direto, soja

ABSTRACT - The experiment was carried out in a Roundup Ready ${ }^{\circledR}$ commercial soybean field in the Pontal do Paranapanema region in Euclides da Cunha Paulista-SP, located 20 43' $11^{\prime}$ 'S and $50^{\circ} 10^{\prime} 20^{\prime \prime} \mathrm{W}, 270 \mathrm{~m}$ altitude. The experimental phase was carried out from December 2006 to April 2007, under no-tillage system. The soil classification is sandy clay loam Argisol. This work aimed to evaluate the efficiency of Roundup Transorb ${ }^{\circledR}$ glyphosate formulation selectivity associated with the herbicides diclosulam, cloransulam-methyl, flumioxazina and S-metolachlor undertwo spray modalities (single, with glyphosate associated to the herbicides and sequential, with only glyphosate)

1 Recebido para publicação em 30.6.2008 e na forma revisada em 5.6.2009.

Parte do trabalho de graduação do primeiro autor apresentado à FCAV/UNESP - Jaboticabal-SP,

2 Mestrando do Programa de Pós-Graduação em Produção Vegetal, Faculdade de Ciências Agrárias e Veterinárias, Universidade Estadual Paulista -FCAV/UNESP, 14884-900 Jaboticabal-SP, <marioviracopos1@ hotmail.com>; ${ }^{3}$ Professor, Dr., Núcleo de Estudos e Pesquisas Ambientais em Matologia - NEPEAM do Dep. de Fitossanidade - FCAV/UNESP, Via de Acesso Prof. Paulo Donato Castellane, s/n, 14884-900 Jaboticabal-SP, ${ }^{4}$ Mestrando do Programa de Pós-Graduação em Produção Vegetal - FCAV/UNESP; ${ }^{5}$ Prof., Dr., Universidade Estadual de Goiás - UEG, <ptimossi2004@yahoo.com.br>. 
in tropical Spiderwort (Commelina benghalensis) and little bell (Ipomoea triloba) management during soybean cultivation. The experiment was arranged in a randomized block design, with 12 treatments and 4 replications. Treatments were distributed in a factorial scheme +2 controls (no control and clean field). The factorial scheme $2 \times 5$ comprises two herbicide sprays (single and sequential) and five herbicides (glyphosate, glyphosate + diclosulam, glyphosate + cloransulammethyl, glyphosate + flumioxazin and glyphosate $+S$-metolachlor). Under the conditions and time the herbicides were used as well as spray dosage, the results showed that glyphosate sprayed in a single dose or sequentially, in combination with diclosulan and cloransulam-methyl in the first spray did not cause phyto-intoxication in the soybean plants. The flumioxazin and S-metolachlor combination promoted delay in the growing plants as well as in the complete formation of the culture due to the effect on plant height and branch length. Neither the herbicides tested nor the sequential spray influenced significantly soybean grain production. All treatments using single application or combined with sequential glyphosate spray promoted an excellent control of Commelina benghalensis and Ipomoea triloba.

Keywords: herbicides, weed, non-tillage, soybeans.

\section{INTRODUÇÃO}

Com o passar dos anos, o Brasil expandiu rapidamente sua área de soja, sendo esta cultivada praticamente em todo o território nacional; atualmente, o País e um dos principais produtores dessa leguminosa.

Essa rápida expansão se deveu às características dessa espécie, como: grande adaptação ao solo, inclusive aos de baixa fertilidade, melhorando com o passar dos anos, possibilidade de mecanização total da cultura, boa adaptação ao sistema plantio direto, grande perspectiva do uso direto da soja na alimentação humana e incentivos fiscais.

Um dos grandes problemas da cultura da soja é a infestação por plantas daninhas, que competem intensivamente com a cultura por água, luz, nutrientes e espaço físico, chegando em alguns casos a provocar prejuízos na faixa de 20 a 30\% do custo total da lavoura (Deuber, 1992). O método mais utilizado para controle de plantas daninhas é o uso de herbicidas.

A liberação da soja transgênica possibilitou a utilização da molécula de glyphosate de amplo espectro para o controle das plantas daninhas em pós-emergência, facilitando o manejo e diminuindo custos. Contudo, existem plantas que possuem certo grau de tolerância à molécula de glyphosate, como a trapoeraba (Commelina benghalensis), de modo que, para o efetivo controle, é necessária a associação com outros herbicidas ou aplicações sequenciais de glyphosate.
O objetivo deste estudo foi avaliar a eficácia e seletividade de glyphosate na formulação Roundup Transorb ${ }^{\circledR}$, associado aos herbicidas diclosulam, cloransulam-methyl, flumioxazina e S-metolachlor em duas modalidades de aplicação (única e sequencial), no manejo das plantas daninhas trapoeraba (Commelina benghalensis) e corda-de-viola (Ipomoea triloba) durante o cultivo da soja transgênica.

\section{MATERIAL E MÉTODOS}

O ensaio foi instalado em área de plantio comercial de soja geneticamente modificada resistente ao glyphosate, no municipio de Euclides da Cunha Paulista-SP, na região do Pontal do Paranapanema, localizada a 20 43' $11^{\prime \prime} \mathrm{S}$ e $50^{\circ} 10^{\prime} 20^{\prime \prime} \mathrm{W}$, com uma altitude de $270 \mathrm{~m}$. O período experimental em campo foi de dezembro de 2006 a abril de 2007, em uma área com solo classificado como textural franco-argilo arenoso (68\% de argila, 4\% de silte e $28 \%$ de areia), na qual a temperatura média foi de $25{ }^{\circ} \mathrm{C}$ e o índice pluviométrico de $800 \mathrm{~mm}$.

Antes do plantio da soja (cultivar Monsoy $7908 \mathrm{RR}^{\circledR}$ ), a área experimental foi dessecada com glyphosate na dose de 4,0 $\mathrm{L} \mathrm{ha}^{-1}$ do produto comercial, combinado com 2,4-D a $0,7 \mathrm{~L} \mathrm{ha}^{-1}$ do produto comercial e óleo mineral (4,0 L ha-1), com o objetivo de eliminar as plantas daninhas, proporcionando melhores condições para a germinação e instalação da cultura. 
A semeadura foi realizada no dia $27 \mathrm{de}$ dezembro de 2006, com espaçamento entrelinhas de $0,45 \mathrm{~m}$ e quantidade de sementes suficiente para um estande final de 10-15 plantas por metro. Na adubação de semeadura foram utilizados $250 \mathrm{~kg} \mathrm{ha}^{-1}$ da fórmula 00-20-04, com base na análise do solo realizada na área experimental.

O delineamento experimental utilizado foi de blocos ao acaso, com 12 tratamentos e quatro repetições (Tabela 1). As parcelas experimentais foram constituídas de nove linhas, com $6 \mathrm{~m}$ de comprimento, considerando-se como área útil os $2 \mathrm{~m}$ das sete linhas centrais.

Os tratamentos foram estabelecidos no esquema fatorial $2 \times 5$, mais duas testemunhas. As variáveis do fatorial foram duas condições de aplicação dos herbicidas (única e sequencial apenas com glyphosate) e cinco tratamentos herbicidas na primeira aplicação. Uma das testemunhas foi mantida no limpo por capinas periódicas, e a outra permaneceu sem qualquer controle das plantas daninhas durante todo o ciclo da soja.

A primeira aplicação do glyphosate e de suas combinações com outros produtos foi realizada no momento em que as plantas de soja apresentavam o primeiro trifólio totalmente aberto (estádio V1). Na aplicação foi utilizado um pulverizador costal com pressão constante mantida por $\mathrm{CO}_{2}$ a $2 \mathrm{kgf} \mathrm{cm}^{-2}$, munido de barra com quatro bicos e pontas DG 110.02 e consumo de calda de $200 \mathrm{~L} \mathrm{ha}^{-1}$. Já a segunda aplicação (sequencial) foi realizada quando as plantas de soja apresentavam de dois a três trifólios abertos (estádios V2 e V3), 14 dias após a primeira aplicação. As condições ambientais no momento das aplicações dos tratamentos foram: temperatura média de $25^{\circ} \mathrm{C}$, umidade relativa média de $77,5 \%$ e velocidade do vento de $3 \mathrm{~km} \mathrm{~h}^{-1}$.

A comunidade infestante era composta por diversas espécies, mas com predominância de corda-de-viola (Ipomoea triloba) e trapoeraba (Commelina benghalensis); no momento da primeira aplicação ambas encontravam-se no estádio de duas a seis folhas, apresentandose vigorosas e, aparentemente, em plena atividade fotossintética.

A colheita ocorreu no dia 6 de abril de 2007. $\mathrm{Na}$ área útil das parcelas, a colheita foi manual, logo após as plantas atingirem o estádio R8 (maturidade de colheita). Em cada parcela foram colhidos $3 \mathrm{~m}$ das duas linhas centrais e contado o estande final das plantas de soja. Em seguida, as plantas colhidas em cada tratamento foram devidamente identificadas e armazenadas em local seco e arejado até o início das avaliações.

Tabela 1 - Tratamentos utilizados no controle químico de Commelina benghalensis e Ipomoea triloba na cultura da soja transgênica. Euclides da Cunha Paulista-SP, 2006/2007

\begin{tabular}{|c|c|c|c|}
\hline Tratamento e Herbicida & $\begin{array}{c}\text { Dose } \\
\text { p.c. }\left(\mathrm{L} \mathrm{ou} \mathrm{g} \mathrm{ha}^{-1}\right)\end{array}$ & Sequencial & $\begin{array}{c}\text { Dose } \\
\text { p.c. }\left(\mathrm{L} \mathrm{ha}^{-1}\right)\end{array}$ \\
\hline Testemunha no limpo & --- & --- & --- \\
\hline Testemunha no mato & --- & --- & --- \\
\hline Glyphosate $^{1 /}$ & 2,0 & $\begin{array}{c}--- \\
---\end{array}$ & --- \\
\hline Glyphosate + diclosulam ${ }^{2 /}$ & $2,0+41,7$ & --- & --- \\
\hline 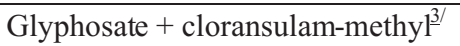 & $2,0+47,6$ & $\begin{array}{c}--- \\
---\end{array}$ & --- \\
\hline Glyphosate + flumioxazin ${ }^{4 /}$ & $2,0+50$ & $\begin{array}{c}-- \\
--\end{array}$ & --- \\
\hline Glyphosate + S-metolachlor $^{5 /}$ & $2,0+2,0$ & ---- & --- \\
\hline Glyphosate & $2,0+1,5$ & glyphosate & 1,5 \\
\hline Glyphosate + diclosulam & $2,0+41,7$ & glyphosate & 1,5 \\
\hline Glyphosate + cloransulam-methyl & $2,0+47,6$ & glyphosate & 1,5 \\
\hline Glyphosate + flumioxazin & $2,0+50$ & glyphosate & 1,5 \\
\hline Glyphosate + S-metolachlor & $2,0+2,0$ & glyphosate & 1,5 \\
\hline
\end{tabular}

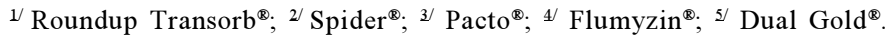


Por ocasião da colheita, foram coletadas dez plantas de soja ao acaso por parcela, para avaliação dos seguintes parâmetros e respectivos critérios utilizados: altura da planta, altura da inserção da primeira vagem e número de vagens.

Para obtenção dos dados de produção, os grãos colhidos na área útil de cada parcela foram pesados e a umidade de cada tratamento foi corrigida para $12 \%$. Para isso, foram determinados o peso dos grãos úmidos e o peso dos grãos secos (após a permanência de 24 horas na estufa de fluxo de ar continuo a $50{ }^{\circ} \mathrm{C}$ ). $\mathrm{O}$ cálculo da umidade permitiu a correção dos pesos da produção de grãos.

As avaliações de eficácia de controle das plantas daninhas foram realizadas aos 15, 30 e 45 dias após a aplicação (DAA) dos tratamentos. Foram dadas notas visuais de controle para cada tratamento, numa escala percentual de 0 a 100, em que zero representava nenhum controle e 100, controle total das plantas invasoras. Em cada parcela foram atribuídas notas de controle para corda-de-viola (Ipomoea triloba), trapoeraba (Commelina benghalensis) e uma nota para a comunidade infestante em geral. As avaliações dos sintomas de toxidade na soja foram realizadas conforme a tabela de notas da SBCPD (1995) e Alam (1974), simultaneamente às avaliações de controle das plantas daninhas, isto é, aos 15, 30 e 45 dias após aplicação, para que fosse possivel detectar alguma interação entre os herbicidas associados.

\section{RESULTADOS E DISCUSSÃO}

Não ocorreu efeito significativo da aplicação única ou da sequencial, bem como de todas as combinações de herbicidas testadas, sobre a altura de inserção da primeira vagem, o número de vagem por plantas, a altura das plantas, o estande de plantas de soja e a produção de grãos. A aplicação sequencial não afetou negativamente os parâmetros produtivos da soja, evidenciando seletividade à cultura, e o herbicida não promove ganhos na produtividade, e sim evita perdas (Tabela 2).

A aplicação do glyphosate e de suas combinações com outros herbicidas não afetou significativamente o número de vagem por planta e a produção de grãos. A altura da primeira vagem foi reduzida significativamente pelas combinações do glyphosate com os herbicidas flumioxazin e S-metolachlor, podendo influenciar diretamente a colheita mecanizada. Para a altura de inserção da primeira vagem não ocorreu diferença estatística entre as plantas das testemunhas capinada e não capinada, evidenciando que a pressão de interferência das plantas daninhas não foi suficiente para afetar essa característica da soja.

A altura das plantas de soja também foi alterada pela interferência das plantas daninhas e aplicação dos herbicidas. Na testemunha não capinada, a altura média das plantas de soja foi maior que na testemunha no limpo, sugerindo estiolamento, devido à competição por luz. A menor altura das plantas foi observada na combinação de glyphosate e S-metolachlor, com alto efeito de fitointoxicação, ocorrendo também redução significativa na aplicação do glyphosate com o flumioxazin. Entre os tratamentos com herbicidas, a maior altura de planta foi verificada nas parcelas que receberam apenas glyphosate e sua combinação com cloransulam-methyl.

O aumento na altura das plantas representa um fator de busca de adaptação à competição futura com plantas vizinhas e assemelha-se aos efeitos do estiolamento das plantas. Merotto Jr. et al. (2002), von Armin \& Deng (1996) e Jersen et al. (1998) ressaltam ainda que o aumento da altura das plantas em virtude da diminuição da qualidade da luz expressa o resultado da alteração de processos fisiológicos relacionados à dinâmica hormonal e à divisão celular, podendo ainda causar a redução da capacidade da planta de absorver nutrientes e água e realizar fotossíntese (Rajcan \& Swanton, 2001).

O estande da cultura (Tabela 2) não foi afetado pela interferência das plantas daninhas, e, entre os tratamentos herbicidas, os valores observados nas parcelas que receberam a combinação de glyphosate com flumioxazin foram inferiores ao observado nas parcelas com aplicação de glyphosate isolado e sua combinação com cloransulam-methyl.

Nenhum desses efeitos observados foi suficiente para afetar a produção de grãos pela 
Tabela 2 - Médias dos valores de alturas de plantas e de inserção da primeira vagem, estande de plantas, número de vagens por planta e produção de grãos de soja, observadas no desdobramento do fatorial segundo suas variáveis principais e os respectivos resultados da análise de variância dos dados. Euclides da Cunha Paulista-SP, 2006/2007

\begin{tabular}{|c|c|c|c|c|c|}
\hline \multirow[t]{2}{*}{ Tratamento } & $\begin{array}{c}\text { Altura da } \\
\text { primeira } \\
\text { vagem }\end{array}$ & $\begin{array}{l}\text { Vagens por } \\
\text { planta }\end{array}$ & $\begin{array}{l}\text { Altura das } \\
\text { plantas }\end{array}$ & Estande & $\begin{array}{l}\text { Produção de } \\
\text { grãos }\end{array}$ \\
\hline & $(\mathrm{cm})$ & (número) & $(\mathrm{cm})$ & $\left(\right.$ plantas $\left.\mathrm{m}^{-1}\right)$ & $\left(\mathrm{kg} \mathrm{ha}^{-1}\right)$ \\
\hline \multicolumn{6}{|c|}{ Número de aplicações } \\
\hline Aplic ação Única & $20,53 \mathrm{a}$ & $37,34 \mathrm{a}$ & $88,44 \mathrm{a}$ & $82,35 \mathrm{a}$ & $1.937,17 \mathrm{a}$ \\
\hline Sequencial & $21,76 \mathrm{a}$ & $30,09 \mathrm{a}$ & $87,71 \mathrm{a}$ & $82,75 \mathrm{a}$ & $1.845,49 \mathrm{a}$ \\
\hline Teste F & $1,54^{\mathrm{ns}}$ & $0,09^{\mathrm{ns}}$ & $0,24^{\mathrm{ns}}$ & $0,02^{\mathrm{ns}}$ & $1,44^{\mathrm{ns}}$ \\
\hline Dms & 2,01 & 4,44 & 3,07 & 6,08 & 155,75 \\
\hline \multicolumn{6}{|c|}{ Herbicidas } \\
\hline Glyphosate & $23,95 \mathrm{a}$ & $36,43 \mathrm{a}$ & $100,93 \mathrm{a}$ & $87,75 \mathrm{a}$ & $1.816,14 \mathrm{a}$ \\
\hline Glyphosate + diclosulam & $21,17 \mathrm{ab}$ & $34,63 \mathrm{a}$ & $93,56 \mathrm{~b}$ & $86,50 \mathrm{ab}$ & $1.748,71 \mathrm{a}$ \\
\hline Glyphosate + cloransulam-methyl & $24,26 \mathrm{a}$ & $32,03 \mathrm{a}$ & $98,76 \mathrm{ab}$ & $89,37 \mathrm{a}$ & $1.802,94 \mathrm{a}$ \\
\hline Glyphosate + flumyoxazin & $18,83 \mathrm{~b}$ & $41,46 \mathrm{a}$ & $77,11 \mathrm{c}$ & $73,25 \mathrm{~b}$ & $2.009,19 \mathrm{a}$ \\
\hline Glyphosate + S-metolachlor & $17,51 \mathrm{~b}$ & $40,50 \mathrm{a}$ & $70,01 \mathrm{~d}$ & $75,87 \mathrm{ab}$ & $2.079,66 \mathrm{a}$ \\
\hline Teste $\mathrm{F}$ & $7,40 * *$ & $2,63^{\mathrm{ns}}$ & $66,22 * *$ & $4,93 * *$ & $2,84 *$ \\
\hline $\mathrm{Dms}$ & 4,50 & 9,96 & 6,89 & 13,63 & 348,83 \\
\hline Interação Ax B & $1,00^{\mathrm{ns}}$ & $1,76^{\mathrm{ns}}$ & $1,28^{\mathrm{ns}}$ & $0,52^{\mathrm{ns}}$ & $0,25^{\mathrm{ns}}$ \\
\hline Test. vs Fatorial & $0,25^{\mathrm{ns}}$ & $1,82^{\mathrm{ns}}$ & $38,76 * *$ & $0,24^{\mathrm{ns}}$ & $4,40^{*}$ \\
\hline Test. Limpo & $21,12 \mathrm{a}$ & $32,55 \mathrm{a}$ & $95,57 \mathrm{~b}$ & $78,50 \mathrm{a}$ & $1.770,92 \mathrm{a}$ \\
\hline Test. Mato & $22,37 \mathrm{a}$ & $34,25 \mathrm{a}$ & $103,62 \mathrm{a}$ & $83,00 \mathrm{a}$ & $1.618,78 \mathrm{a}$ \\
\hline Entre test. & $0,32^{\mathrm{ns}}$ & $0,12^{\mathrm{ns}}$ & $5,67 *$ & $0,45^{\mathrm{ns}}$ & $0,79^{\mathrm{ns}}$ \\
\hline $\mathrm{CV}(\%)$ & 14,7 & 19,0 & 5,3 & 11,5 & 13,0 \\
\hline
\end{tabular}

*significativo a $5 \%$; ** significativo a $1 \%$; ${ }^{\text {ns }}$ não significativo.

cultura da soja, porém a média de produção dos tratamentos que compõem o fatorial sobrepujou estatisticamente a média das testemunhas. Nesse caso, não há como concluir por que a média das testemunhas inclui as duas testemunhas: capinada e não capinada.

Com relação ao método de aplicação de herbicidas, única ou sequencial (Tabela 3), aos 15 DAA o método de aplicação não alterou o controle das duas espécies analisadas: para a trapoeraba, a aplicação única obteve $94,8 \%$ de controle, e a sequencial, $94,5 \%$; e para cordade-viola, a aplicação única mostrou $97,7 \%$, e a sequencial, 99,2\%, ou seja, não diferiram entre si.

Para a trapoeraba, aos 30 e 45 DAA ocorreu diferença significativa entre a aplicação única e a sequencial em relação ao seu controle. Houve maior controle na aplicação sequencial: $96,5 \%$ contra $91,8 \%$ na aplicação única aos 30 DAA e $96,8 \%$ contra $91,5 \%$ aos 45 DAA. Esses resultados estão de acordo com os de diversos trabalhos na literatura, os quais mostram que a Commelina benghalensis é uma planta daninha de dificil controle e que com aplicações sequenciais pode-seobter maior sucesso. Procópio et al. (2007) relataram que aplicações isoladas de glyphosate (Roundup Transorb $^{\circledR}$ ) nas doses de 1,0, 2,0 e 3,0 $\mathrm{L} \mathrm{ha}^{-1}$ não resultaram em controle satisfatório da trapoeraba. Rocha et al. (2007), comparando os efeitos de diferentes herbicidas aplicados em pós-emergência sobre C. benghalensis, verificaram que o tratamento com glyphosate aplicado na forma isolada não foi capaz de cessar completamente o desenvolvimento das plantas de $C$. benghalensis.

Para corda-de-viola (Tabela 3) aos 15 DAA e 30 DAA não ocorreu diferença na eficácia de controle quando foi comparada a aplicação única e a sequencial. Aos 45 DAA houve diferença entre métodos de aplicação no controle de corda-de-viola, sendo a aplicação mais eficaz $(99,8 \%)$ que a única $(98,7 \%)$. 
Analisando os niveis de controle da trapoeraba em relação ao fator herbicidas (Tabela 3), observa-se que os tratamentos com apenas o glyphosate aos 15 DAA apresentaram menor eficácia de controle, quando comparados com o tratamento de glyphosate combinado com diclosulam e S-metolachlor. A trapoeraba é tolerante ao glyphosate, igualmente a planta daninha azevém (Lolium mutiflorum), conforme ressaltaram Christoffoleti \& López-Ovejero (2003). Aos 30 DAA, o controle promovido pelo glyphosate isolado foi suplantado pelo proporcionado por sua combinação com diclosulam e cloransulam-methyl. Aos 45 DAA, foram observados valores de controle estatisticamente inferiores nos tratamentos com glyphosate combinado com flumioxazin ou com S-metolachlor, em relação à combinação com diclosulam. No entanto, é importante ressaltar que todos os tratamentos proporcionaram excelente controle de Commelina benghalensis nas três avaliações, ultrapassando o nivel de $90 \%$, e que as diferenças observadas são de natureza estatística, com pouco significado prático, pois estas estão inseridas dentro da margem de erro da avaliação visual.

De certa forma, os resultados obtidos concordam com os apresentados por Galli (1991) e Ramos \& Durigan (1996), nos quais a aplicação do glyphosate associado com outro herbicida resulta em melhor eficácia para o controle da trapoeraba.

Todos os tratamentos herbicidas foram bastante eficazes no controle de Ipomoea triloba, com controle superior a $97 \%$, tanto em aplicação única como na sequencial. Aos 45 DAA, a análise estatística evidenciou melhor controle da aplicação sequencial. No entanto, a diferença é tão pequena que não deve ser considerada do ponto de vista prático, e seu valor é apenas estatístico.

O uso de herbicidas e misturas de herbicidas pode acarretar possiveis efeitos de fitointoxicação quando aplicados na cultura. Esses efeitos podem se traduzir em injúrias para a cultura da soja e alteração das suas características fenológicas, na altura da planta, no número de vagens por planta e na altura da primeira vagem, podendo, em alguns casos, afetar diretamente a produtividade.

Pela análise da Tabela 4, os tratamentos com aplicações únicas e sequenciais não diferenciaram entre si, verificando-se que a aplicação sequencial com glyphosate não causou injúrias à cultura da soja. Analisando

Tabela 3 - Resultados médios das avaliações de controle de Commelina benghalensis e Ipomoea triloba aos 15, 30 e 45 DAA, sob aplicação de glyphosate isolado ou em combinação com outros herbicidas, com e sem aplicação sequencial de glyphosate. Euclides da Cunha Paulista-SP, 2006/2007

\begin{tabular}{|c|c|c|c|c|c|c|}
\hline \multirow{2}{*}{ Tratamento } & \multicolumn{3}{|c|}{ Trapoeraba } & \multicolumn{3}{|c|}{ Corda-de-viola } \\
\hline & $15 \mathrm{DAA}$ & 30 DAA & $45 \mathrm{DAA}$ & $15 \mathrm{DAA}$ & 30 DAA & $45 \mathrm{DAA}$ \\
\hline \multicolumn{7}{|c|}{ Número de aplicações } \\
\hline Aplic ação Única & $94,8 \mathrm{a}$ & $91,8 \mathrm{~b}$ & $91,5 \mathrm{~b}$ & $97,7 \mathrm{a}$ & $98,5 \mathrm{a}$ & $98,7 \mathrm{~b}$ \\
\hline Sequencial & $94,5 \mathrm{a}$ & $96,5 \mathrm{a}$ & $96,8 \mathrm{a}$ & $99,2 \mathrm{a}$ & $99,5 \mathrm{a}$ & $99,8 \mathrm{a}$ \\
\hline Teste F & $0,08^{\mathrm{ns}}$ & $23,60 * *$ & $17,49 * *$ & $3,98^{\mathrm{ns}}$ & $2,37^{\mathrm{ns}}$ & $4,27 *$ \\
\hline Dms & 2,5 & 1,98 & 2,60 & 1,54 & 1,33 & 1,09 \\
\hline \multicolumn{7}{|c|}{ Herbicidas } \\
\hline Glyphosate & $90,0 \mathrm{~b}$ & $90,7 \mathrm{~b}$ & $93,6 \mathrm{ab}$ & $96,5 \mathrm{a}$ & $98,7 \mathrm{a}$ & $99,0 \mathrm{a}$ \\
\hline Glyphosate + diclosulam & $97,5 \mathrm{a}$ & $96,8 \mathrm{a}$ & $97,3 \mathrm{a}$ & $99,2 \mathrm{a}$ & $99,2 \mathrm{a}$ & $100,0 \mathrm{a}$ \\
\hline Glyphosate +cloransulam -methyl & $95,6 \mathrm{ab}$ & $96,2 \mathrm{a}$ & $97,0 \mathrm{ab}$ & $97,8 \mathrm{a}$ & $99,2 \mathrm{a}$ & $100,0 \mathrm{a}$ \\
\hline Glyphosate + flumyoxazin & $93,2 \mathrm{ab}$ & $92,5 \mathrm{ab}$ & $91,5 \mathrm{~b}$ & $98,8 \mathrm{a}$ & $99,2 \mathrm{a}$ & $99,3 \mathrm{a}$ \\
\hline Glyphosate + S-metolachlor & $97,0 \mathrm{a}$ & $94,3 \mathrm{ab}$ & $91,5 \mathrm{~b}$ & $99,7 \mathrm{a}$ & $98,7 \mathrm{a}$ & $97,8 \mathrm{a}$ \\
\hline Teste $\mathrm{F}$ & $5,1207 * *$ & $5,5921 * *$ & $4,0906^{*}$ & $2,3510^{\mathrm{ns}}$ & $0,1424^{\mathrm{ns}}$ & $2,1867^{\mathrm{ns}}$ \\
\hline Dms & 5,6 & 4,46 & 5,85 & 3,47 & 2,99 & 2,45 \\
\hline $\mathrm{A} \times \mathrm{B}$ & $1,6750^{\mathrm{ns}}$ & $4,2698^{* *}$ & $1,5395^{\mathrm{ns}}$ & $3,5718^{*}$ & $1,0677^{\mathrm{ns}}$ & $1,2502^{\mathrm{ns}}$ \\
\hline $\mathrm{CV} \%$ & 4,07 & 3,24 & 4,25 & 2,41 & 2,07 & 1,69 \\
\hline
\end{tabular}

*significativo a $5 \%$; $* *$ significativo a $1 \%$; ${ }^{\text {ns }}$ não significativo. 
Tabela 4 - Avaliações dos sintomas de fitointoxicação nas plantas de soja, promovidos pela aplicação de glyphosate isolado ou em combinação com outros herbicidas, em aplicação única ou sequencial. Euclides da Cunha Paulista-SP, 2006/2007

\begin{tabular}{|l|c|c|c|}
\hline \multicolumn{1}{|c|}{ Tratamento } & $15 \mathrm{DAA}$ & $30 \mathrm{DAA}$ & $45 \mathrm{DAA}$ \\
\hline \multicolumn{3}{|c|}{ Número de aplicação } \\
\hline Aplicação Única & $3,2 \mathrm{a}$ & $2,3 \mathrm{a}$ & $2,0 \mathrm{a}$ \\
\hline Sequencial & $3,1 \mathrm{a}$ & $2,1 \mathrm{a}$ & $2,0 \mathrm{a}$ \\
\hline Teste F & $0,9681^{\mathrm{ns}}$ & $1,1302^{\mathrm{ns}}$ & $0,0000^{\mathrm{ns}}$ \\
\hline Dms & 0,31 & 0,28 & 0,21 \\
\hline \multicolumn{3}{|c|}{ Herbicidas } \\
\hline Glyphosate & $1,5 \mathrm{c}$ & $1,1 \mathrm{c}$ & $1,0 \mathrm{c}$ \\
\hline Glyphosate + diclosulam & $2,2 \mathrm{~b}$ & $1,5 \mathrm{c}$ & $1,0 \mathrm{c}$ \\
\hline Glyphosate +cloransulam -methyl & $1,5 \mathrm{c}$ & $1,1 \mathrm{c}$ & $1,0 \mathrm{c}$ \\
\hline Glyphosate + flumyoxazin & $5,0 \mathrm{a}$ & $3,2 \mathrm{~b}$ & $2,8 \mathrm{~b}$ \\
\hline Glyphosate + S-metolachlor & $5,6 \mathrm{a}$ & $4,1 \mathrm{a}$ & $4,1 \mathrm{a}$ \\
\hline Teste F & $135,9681^{* *}$ & $76,4163^{* *}$ & $154,2026^{* *}$ \\
\hline Dms & 0,70 & 0,65 & 0,47 \\
\hline A x B & $1,5060^{\mathrm{ns}}$ & $0,8163^{\text {ns }}$ & $0,5819^{\text {ns }}$ \\
\hline CV \% & 15,18 & 20,05 & 16,38 \\
\hline
\end{tabular}

*significativo a $5 \% ; * *$ significativo a $1 \%$; ${ }^{\text {ns }}$ não significativo.

os niveis de fitointoxicação em relação ao fator herbicida, observa-se que aos 15 DAA os tratamentos apresentavam maiores niveis de fitointoxicação, destacando os tratamentos com glyphosate e glyphosate + cloransulammethyl, com os menores valores de intoxicação, e o tratamento com glyphosate + S-metolachlor, com o maior nível. Correia \& Durigan (2007) compararam várias formulações comerciais de glyphosate e concluíram que não havia diferenças em termos de sintomas de fitointoxicação nas plantas de soja. Procópio et al. (2007) ressaltaram também que não foram observados sintomas de intoxicação nas plantas de soja Roundup Ready ${ }^{\circledR}$ promovidos pela aplicação isolada de glyphosate na formulação Roundup Transorb ${ }^{\circledR}$, independentemente da dose testada $\left(1,0 \mathrm{~L} \mathrm{ha}^{-1}, 2,0 \mathrm{~L} \mathrm{ha}^{-1}\right.$ e 3,0 $\mathrm{L} \mathrm{ha}^{-1}$ ).

Nas avaliações seguintes, aos 30 e 45 DAA (Tabela 4), foi observada diminuição na fitointoxicação ocasionada pelos herbicidas. Aos 45 DAA, os tratamentos glyphosate, glyphosate + diclosulam e glyphosate + cloransulam-methyl se igualaram como os de menores níveis de fitointoxicação (nota 1, nenhum efeito), e os tratamentos glyphosate + flumioxazin e glyphosate + S-metolachlor, com os de maiores niveis.
Nos tratamentos glyphosate + flumioxazin e glyphosate + S-metolachlor, as plantas de soja encontravam-se extremamente debilitadas, não havendo o fechamento das entrelinhas, o que ofereceu oportunidade para o crescimento das plantas daninhas (trapoeraba). Isso pode ser explicado pelo fato de o herbicida S-metolachlor ter sido aplicado em pós-emergência; segundo Rodrigues \& Almeida (2005), é um herbicida registrado para o controle de plantas daninhas na soja em pré-emergência.

Nas condições em que foi conduzida a fase experimental, foi possivel concluir que o herbicida glyphosate aplicado em dose única ou sequencial e suas combinações com diclosulam e cloransulam-methyl na primeira aplicação não promovem efeitos de fitointoxicação em plantas de soja. A combinação com flumioxazin e S-metolachlor promoveu atrasos no crescimento das plantas e no fechamento da cultura, em função do efeito na altura dos indivíduos, porém nenhum dos tratamentos herbicidas nem a aplicação sequencial influenciaram significativamente a produção de grãos da cultura da soja. Todos os tratamentos em aplicação única ou complementados com aplicação sequencial de glyphosate promoveram excelente controle de Commelina benghalensis e Ipomoea triloba. 


\section{LITERATURA CITADA}

ASSOCIACION LATINO AMERICANA DE MALEZAS ALAM. Recomendaciones sobre unificacion de los sistemas de evaluacion em ensayos de control de malezas. ALAM, v. 1, p. $35-38,1974$

CHRISTOFFOLETI, P. J.; LÓPEZ-OVEJERO, R. F. Principais aspectos da resistência de plantas daninhas ao herbicida glyphosate. Planta Daninha, v. 21, n. 3, p. $507-515,2003$.

CORREIA, N. M.; DURIGAN, J. C. Seletividade de diferentes herbicidas à base de glyphosate à soja RR. Planta Daninha, v. 25, n. 2, p. 375-379, 2007.

DEUBER, R. Ciência das plantas daninhas: fundamentos. Jaboticabal: FUNEP, 1992. v. 1. 431 p.

DURIGAN, J. C. Efeito de adjuvantes na calda e no estádio de desenvolvimento das plantas, no controle de capimcolonião (Panicum maximum) com glyphosate. Planta Daninha, v. 10, n. 1, p. 39-44, 1996

GALLI, A. J. B. Avaliação da eficiência de glyphosate em diversos produtos no controle de Commelina virginica (trapoeraba) em citros. In: CONGRESSO BRASILEIRO DE PLANTAS DANINHAS, 18., 1991, Brasília. Resumos... Brasília: SBHED, 1991. p. 104-105.

JERSEN, P. J.; HANGARTER, R. P.; ESTELLE, M. Auxin transport is required for hypocotyls elongation in lightgrowth but not dark-growth Arabdopsis. Plant Physiol. v. 116, n. 2 , p. $455-462,1998$
MEROTTO Jr., A.; VIDAL, R. A.; FLECK, N. G. Interferência das plantas daninhas sobre o desenvolvimento inicial das plantas de soja e arroz através da qualidade da luz. Planta Daninha, v. 20, n. 1, p. 9-16, 2002

PROCÓPIO, S. O. et al. Utilização de chlorimuron-ethyl e imazethapyr na cultura da soja Roundup Ready ${ }^{\circledR}$. Planta

Daninha, v. 25, n. 2, p. 365-373, 2007.

RAJCAN, I.; SWANTON, C. J. Understading maize-weed competition: resource competition, light quality and the whole plant. Field Crops Res., v. 71, n. 2, p. 139-150, 2001.

RAMOS, H. H.; DURIGAN, J. C. Avaliação da eficiência da mistura pronta de glyphosate $+2,4-\mathrm{D}$ no controle da Commelina virginica L. em citros. Planta Daninha, v. 14 n. 1, p. 33-41, 1996.

ROCHA, D. C. et al. Efeito de herbicidas sobre quatro espécies de trapoeraba. Planta Daninha, v. 25, n. 2, p. $359-364,2007$.

RODRIGUES, B. N.; ALMEIDA, F. S. Guia de herbicidas. 5.ed. Londrina: Grafmarke, 2005. 591 p.

SOCIEDADE BRASILEIRA DA CIÊNCIA DAS PLANTAS DANINHAS - SBCPD. Procedimentos para instalação, avaliação e análise de experimentos com herbicidas. Londrina: 1995. $42 \mathrm{p}$.

VON ARMIN, A.; DENG, X, W. Light control of seedling development. Ann. Rev. Physiol. Plant Molec. Biol., v. 47, p. 215-246, 1996. 